\title{
Metoprolol Does Not Effect Myocardial Fractional Flow Reserve in Patients With Intermediate Coronary Stenoses
}

\author{
Murat OzDEMIR, ${ }^{1}$ MD, Guliz Erdem YAZICI, ${ }^{1}$ MD, Sedat TuRKoglu, ${ }^{1}$ MD, \\ Timur TIMURKAYNAK, ${ }^{1} \mathrm{MD}$, and Atiye CENGEL, ${ }^{1} \mathrm{MD}$
}

\begin{abstract}
SUMMARY
Objective: Myocardial fractional flow reserve (FFR) is utilized to determine the hemodynamic significance of coronary stenoses. We sought to determine the effect, if any, of metoprolol on FFR in patients with coronary stenoses of intermediate severity.
\end{abstract}

Methods and results: Eighteen patients (10 males, mean age, $59.4 \pm 7.7$ years) with isolated, intermediate (30\% to $70 \%$ narrowing on coronary angiogram) lesions on the proximal LAD and a preserved ejection fraction, underwent FFR measurement using a 0.014 inch pressurewire and intracoronary adenosine injection before and after intravenous metoprolol at a dose that achieved at least a $10 \%$ decrease in the heart rate. Heart rate dropped significantly with metoprolol. At the premetoprolol measurement, aortic pressure $(\mathrm{Pa})$ remained essentially the same $(105.7 \pm 11.5$ versus $105.6 \pm 11.6 \mathrm{mmHg}, P$ $>0.05$ ) and distal coronary pressure (Pd) dropped significantly by $9 \%$ from $96.3 \pm 12.7$ to $87.4 \pm 13.4 \mathrm{mmHg}(P<0.001)$ after adenosine injection yielding an $\mathrm{FFR}_{1}$ of $0.83 \pm$ 0.07 . At the postmetoprolol phase, Pa dropped nonsignificantly by $2 \%$ from $104.4 \pm 12.8$ to $102.4 \pm 14.3 \mathrm{mmHg}(P=0.09)$ and Pd dropped significantly by $11 \%$ from $95.7 \pm 14.4$ to $85.3 \pm 16.4 \mathrm{mmHg}(P<0.001)$ after adenosine injection, yielding an $\mathrm{FFR}_{2}$ of $0.83 \pm$ 0.08 , which was almost exactly the same as $\mathrm{FFR}_{1}(P>0.05)$.

Conclusion: In this study, FFR was found not to be influenced by metoprolol treatment in patients with intermediate coronary stenoses and a preserved ejection fraction. (Int Heart J 2007; 48: 477-483)

Key words: Metoprolol, Myocardial fractional flow reserve

Myocardial fractional flow reserve (FFR) is a widely used index of the hemodynamic significance of coronary stenoses. Based on intracoronary measurement of pressure proximal and distal to a lesion during maximum coronary hyperemia, an FFR value of 0.75 distinguishes lesions of hemodynamic significance with a high sensitivity and specificity. ${ }^{1,2)}$ It is used more and more frequently in many catheterization laboratories to guide clinical decision-making

From the ${ }^{1}$ Department of Cardiology, Gazi University School of Medicine, Ankara, Turkey.

Address for correspondence: Murat Özdemir, MD, Gazi University School of Medicine, Department of Cardiology, 06500, Besevler, Ankara, Turkey.

Received for publication March 19, 2007.

Revised and accepted June 4, 2007. 
with regard to revascularization of especially intermediate coronary stenoses so that intermediate lesions with an FFR above 0.75 are safely left unrevascularized with a favorable long-term prognosis. ${ }^{3-5)}$

Most patients with coronary artery disease and intermediate coronary stenoses use a variety of cardiac medications that most of the time include betablockers, a group of drugs which have been shown to influence coronary flow reserve, another index of coronary lesion severity. ${ }^{6)}$ Myocardial FFR has previously been shown to be independent of hemodynamic changes including heart rate, blood pressure, and contractility, ${ }^{7)}$ but no study has specifically evaluated the effect of beta-blockers on FFR. Accordingly, the aim of this study was to examine the effect of the beta-blocker metoprolol on FFR measurements in patients with coronary stenoses of intermediate severity.

\section{Methods}

Patients with coronary artery disease who were scheduled for FFR evaluation of intermediate coronary stenoses (30\% to $70 \%$ luminal narrowing, as assessed by quantitative coronary angiography) were studied. To be eligible for the study, the patients had to have an isolated intermediate coronary stenosis in a proximal coronary artery segment and no myocardial infarction in the territory supplied by that artery. Consecutive lesions along the same coronary artery were excluded. Patients with contraindications to beta-blockers were also excluded. Written informed consent was obtained before FFR measurement in all patients.

In patients using beta-blockers, the drug was stopped gradually for at least 3 half-lives before the FFR measurement. The patients were taken to the catheterization laboratory in the fasting state. After systemic anticoagulation by 10,000 units of intravenous heparin, the coronary artery was catheterized by a guiding catheter with no side holes. The intermediate stenosis was crossed with a specially designed 0.014 inch coronary guide wire (Pressurewire, Radi Medical Systems, Uppsala, Sweden) having a pressure sensor on its distal part so that the sensor lied distal to the stenosis in question. The mean pressure recorded through the guiding catheter represented $\mathrm{Pa}$ and the mean pressure recorded through the pressure wire represented Pd. FFR was defined as $\mathrm{Pd} / \mathrm{Pa}$ during coronary hyperemia which was achieved by intracoronary bolus injection of adenosine, $50 \mu \mathrm{g}$ for the left and $40 \mu \mathrm{g}$ for the right coronary artery. After the initial FFR measurement, $5 \mathrm{mg}$ metoprolol was given intravenously. In case this first $5 \mathrm{mg}$ dose did not achieve at least a $10 \%$ decrease in the heart rate, additional $2.5 \mathrm{mg}$ doses were given until such a decrease in rate was recorded and then the second FFR measurement was performed exactly in the same manner as the first one.

Statistical analysis: Data are given as the mean \pm standard deviation for continu- 
ous variables and as absolute numbers for categorical variables. Analysis was performed using a commercially available software (SPSS 10.0 for Windows). Preliminary data analysis with the Kolmogorov-Smirnov test showed no significant deviation from normality. The paired Student's $t$ test was therefore used to assess differences between repeated measurements. A 2-sided $P$ value below 0.05 was considered statistically significant.

\section{Results}

The baseline characteristics of the study population are given in Table I. The patient population was a low-risk one with preserved ejection fraction. The lesion

Table I. Baseline Characteristics of the Study Population $(n=18)$

\begin{tabular}{lc}
\hline Age (years) & $59.4 \pm 7.7$ \\
Sex (M/F) & $10 / 8$ \\
Risk factors & \\
Hypertension & $12(67 \%)$ \\
Diabetes mellitus & $7(39 \%)$ \\
Smoking & $5(28 \%)$ \\
Hyperlipidemia & $8(44 \%)$ \\
Clinical history & \\
Stable angina & $4(22 \%)$ \\
Unstable angina & $4(22 \%)$ \\
Atypical angina & $10(56 \%)$ \\
History of previous MI & $3(17 \%)$ \\
Resting ECG & $11(61 \%)$ \\
Normal & $6(33 \%)$ \\
Nonspecific ST-T changes & $1(6 \%)$ \\
Pathological Q waves & $61 \pm 10$ \\
Echocardiographic ejection fraction & $2(11 \%)$ \\
Echocardiographic LV hypertrophy & \\
Accompanying significant CAD & $2(11 \%)$ \\
2-vessel disease & $2(11 \%)$ \\
1-vessel disease & $45.3 \pm 9.8 \%$ \\
Mean percent stenosis (FFR lesion) &
\end{tabular}

$\mathrm{MI}$ indicates myocardial infarction; CAD, coronary artery disease; and LV, left ventricular.

Table II. Initial FFR $\left(\mathrm{FFR}_{1}\right)$ Measurements

\begin{tabular}{lccc}
\hline & Basal & After adenosine & $P$ \\
\hline Heart rate $(\mathrm{bpm})$ & $84.3 \pm 9.9$ & $84.5 \pm 9.8$ & $\mathrm{NS}$ \\
$\mathrm{Pa}(\mathrm{mmHg})$ & $105.7 \pm 11.5$ & $105.6 \pm 11.6$ & $\mathrm{NS}$ \\
$\mathrm{Pd}(\mathrm{mmHg})$ & $96.3 \pm 12.7$ & $87.4 \pm 13.4$ & $<0.001$ \\
$\mathrm{FFR}_{1}$ & - & $0.83 \pm 0.07$ & - \\
\hline
\end{tabular}

$\mathrm{Pa}$ indicates aortic pressure; and $\mathrm{Pd}$, distal coronary pressure. 
across which the FFR measurement was performed was located on the proximal left anterior descending coronary artery (LAD) in all cases. Concomitant significant coronary artery disease ( $>70 \%$ luminal narrowing) was present in 4 patients, 2 -vessel disease in 2, and single-vessel disease in the remaining 2 . The mean percent stenosis of the intermediate lesions over which FFR was measured was 45.3 $\pm 9.8 \%$.

Since the intermediate lesion was located on the LAD in all cases, a $50 \mu \mathrm{g}$ dose of adenosine was utilized in all FFR measurements. The heart rate was 84.3 \pm 9.9 beats per minute (bpm) during the initial FFR measurement. After intracoronary adenosine injection, no significant change was observed in either the heart rate or $\mathrm{Pa}$, but $\mathrm{Pd}$ was significantly decreased by $9 \%$ from $96.3 \pm 12.7$ to $87.4 \pm$ $13.4 \mathrm{mmHg}$, yielding an initial FFR $\left(\mathrm{FFR}_{1}\right)$ of $0.83 \pm 0.07$ (Table II).

The mean metoprolol dose needed to achieve at least a $10 \%$ decrease in the heart rate was $5.42 \pm 1.28 \mathrm{mg}$. The heart rate dropped significantly from $84.3 \pm$ $9.9 \mathrm{bpm}$ to $71.1 \pm 6.9 \mathrm{bpm}$ after metoprolol injection but no significant change was observed in either Pa or Pd as compared to the premetoprolol phase (Table III).

Table III. Effect of Metoprolol on Basal Hemodynamic Parameters

\begin{tabular}{lccc}
\hline & Basal & After metoprolol & $P$ \\
\hline Heart rate $(\mathrm{bpm})$ & $84.3 \pm 9.9$ & $71.1 \pm 6.9$ & $<0.001$ \\
$\mathrm{~Pa}(\mathrm{mmHg})$ & $105.7 \pm 11.5$ & $104.4 \pm 12.8$ & $\mathrm{NS}$ \\
$\mathrm{Pd}(\mathrm{mmHg})$ & $96.3 \pm 12.7$ & $95.7 \pm 14.4$ & $\mathrm{NS}$ \\
\hline
\end{tabular}

Table IV. Second FFR $\left(\mathrm{FFR}_{2}\right)$ Measurements (postmetoprolol phase)

\begin{tabular}{lccc}
\hline & Basal & After adenosine & $P$ \\
\hline Heart rate $(\mathrm{bpm})$ & $71.1 \pm 6.9$ & $71.6 \pm 7.4$ & NS \\
$\mathrm{Pa}(\mathrm{mmHg})$ & $104.4 \pm 12.8$ & $102.4 \pm 14.3$ & $\mathrm{NS}$ \\
$\mathrm{Pd}(\mathrm{mmHg})$ & $95.7 \pm 14.4$ & $85.3 \pm 16.4$ & $<0.001$ \\
$\mathrm{FFR}_{2}$ & - & $0.83 \pm 0.08$ & - \\
\hline
\end{tabular}

Table V. Adenosine-induced Values in $\mathrm{Pa}$ and $\mathrm{Pd}$ in the Pre- and Postmetoprolol Measurements

\begin{tabular}{rrrc}
\hline & Premetoprolol & Postmetoprolol & $P$ \\
\hline $\mathrm{Pa}$ & $105.6 \pm 11.6$ & $102.4 \pm 14.3$ & 0.042 \\
$\mathrm{Pd}$ & $87.4 \pm 13.4$ & $85.3 \pm 16.4$ & 0.110 \\
\hline
\end{tabular}


After 3 to 5 minutes of rate stabilization postmetoprolol, the second intracoronary adenosine injection was performed and $\mathrm{FFR}_{2}$ was measured. At this second measurement, adenosine again led to a significant $11 \%$ decrease in Pd with no significant change in heart rate and a nonsignificant $2 \%$ decrease in Pa, yielding a mean $\mathrm{FFR}_{2}$ of $0.83 \pm 0.08$ (Table IV), which was almost identical to FFR $\left(P>0.05\right.$, for comparison of $\mathrm{FFR}_{1}$ versus $\left.\mathrm{FFR}_{2}\right)$.

When we compared adenosine induced $\mathrm{Pa}$ and $\mathrm{Pd}$ values before and after metoprolol injection, $\mathrm{Pa}$ was significantly lower at the postmetoprolol measurement as compared to the premetoprolol one. On the other hand, no significant difference in the respective Pd values was detected (Table V).

\section{DISCUSSION}

Myocardial FFR is a widely used hemodynamic index of coronary lesion severity. It is expressed as the ratio of pressure distal and proximal to a coronary stenosis during maximal coronary hyperemia. With a normal value of 1.0, an FFR below 0.75 is highly sensitive and specific to determine coronary lesions of hemodynamic significance. ${ }^{1,2)}$

The main finding of this study is that FFR measurement in patients with $\mathrm{CAD}$ and preserved ejection fraction and intermediate coronary stenoses is not influenced by metoprolol treatment. To the best of our knowledge, this issue has not been specifically questioned in the literature. Metoprolol, a beta-1 selective beta-blocker, has negative inotropic and chronotropic effects. We utilized intravenous metoprolol in our study and observed a significant negative chronotropic effect at a dose of $5.42 \pm 1.28 \mathrm{mg}$. Although the heart rate was significantly lowered after metoprolol, no significant change was observed in either $\mathrm{Pa}$ or $\mathrm{Pd}$. Under basal conditions, adenosine induced no change in $\mathrm{Pa}$ and a mean $9 \%$ decrease in $\mathrm{Pd}$. On the other hand, under the influence of metoprolol, adenosine led to an $11 \%$ decrease in Pd and a $2 \%$ decrease in Pa. Therefore, FFR, which is expressed as the ratio of $\mathrm{Pd} / \mathrm{Pa}$, remained essentially the same after metoprolol. The significantly lower adenosine induced $\mathrm{Pa}$ (Table $\mathrm{V}$ ) and the nonsignificantly greater adenosine induced decrease (11\% versus $9 \%$ ) in $\mathrm{Pd}$ at the postmetoprolol measurement would be best explained by a decrease in coronary vascular resistance by metoprolol under conditions of maximal hyperemia as shown by Billinger, et al. ${ }^{6}$ )

The independence of myocardial FFR from changes in heart rate, contractility, and blood pressure has previously been shown. ${ }^{7)}$ In their study, 13 stenoses were studied at different hemodynamic loading states. Atrial pacing, nitroprusside, and dobutamine were utilized to induce changes in heart rate, blood pressure, and contractility, respectively. Myocardial FFR was almost exactly the same 
at various hemodynamic loading conditions. The results of this study are in accordance with our findings, because we have shown that myocardial FFR measurement is not influenced by metoprolol, which has negative chronotropic and inotropic effects.

Myocardial FFR measurement is of utmost importance in the evaluation of angiographically intermediate coronary stenoses. Lesions of this sort with no hemodynamic significance, as defined by an FFR above 0.75 , are best left unrevascularized with a favorable long-term prognosis. ${ }^{3-5)}$ Another index utilized to evaluate the hemodynamic significance of coronary stenoses is the coronary flow reserve (CFR) which is described as the ratio of coronary blood flow during maximal hyperemia to resting coronary blood flow. Either positron emission tomography (PET) or intracoronary Doppler techniques can be used to measure CFR. Intracoronary adenosine or an ischemic stimulus may be utilized to induce maximal coronary flow during CFR measurements. Metoprolol has been reported to increase CFR measured by PET in normal subjects. ${ }^{8)}$ A metoprolol-induced increase in maximal coronary flow accompanied by a decrease in resting flow have been observed to be responsible for the metoprolol-induced increase in CFR in normal subjects as measured by PET. ${ }^{8)}$ Contradictory to this, in patients with CAD scheduled for coronary revascularization, metoprolol has been shown to decrease both resting and dipyridamole-induced maximal coronary flow as measured by PET. ${ }^{9)}$

In another study evaluating the effect of metoprolol on CFR measured by intracoronary Doppler utilizing both adenosine and an ischemic stimulus for the induction of maximal hyperemia, metoprolol has been shown to increase CFR. ${ }^{\text {) }}$ The effect of metoprolol in increasing CFR in this study has been attributed to its effect on coronary vascular resistance during maximal coronary hyperemia so that metoprolol had no effect on resting coronary flow but it increased coronary flow by decreasing coronary vascular resistance solely during hyperemia. ${ }^{6}$ )

Although there is an obvious discrepancy between findings regarding the effects of metoprolol on CFR measurements, myocardial FFR has been shown, in our study, to be independent of beta-blocker effects. Therefore, in patients with intermediate coronary stenoses and a preserved ejection fraction using betablockers, FFR should be the preferred method of evaluating stenosis severity. With the available data, we would not consider discontinuation of beta-blocker therapy before FFR measurement.

\section{REFERENCES}

1. Pijls NH, De Bruyne B, Peels K, et al. Measurement of fractional flow reserve to assess the functional severity of coronary artery stenoses. N Engl J Med 1996; 334: 1703-8. 
2. Pijls NH, Van Gelder B, Van der Voort P, et al. Fractional flow reserve: A useful index to evaluate the influence of an epicardial coronary stenosis on myocardial blood flow. Circulation 1995; 92: 3183-93.

3. Bech GJ, De Bruyne B, Bonnier HJ, et al. Long-term follow-up after deferral of percutaneous transluminal coronary angioplasty of intermediate stenosis on the basis of coronary pressure measurement. J Am Coll Cardiol 1998; 31: 841-7.

4. Bech GJ, De Bruyne B, Pijls NH, et al. Fractional flow reserve to determine the appropriateness of angioplasty in moderate coronary stenosis: a randomized trial. Circulation 2001; 103: 2928-34.

5. Ozdemir M, Timurkaynak T, Cemri M, et al. Medium-term follow-up of intermediate coronary stenoses left unrevascularized based on myocardial fractional flow reserve findings. Acta Cardiol 2002; 57: 335-40.

6. Billinger M, Seiler C, Fleisch M, Eberli FR, Meier B, Hess OM. Do beta-adrenergic blocking agents increase coronary flow reserve? J Am Coll Cardiol 2001; 38: 1866-71.

7. Pijls NH. Independence of fractional flow reserve of hemodynamic loading conditions. In: Pijls NH, De Bruyne B, eds. Coronary Pressure. Dordrecht, the Netherlands: Kluwer Academic Publishers; 1997: 156-78.

8. Bottcher M, Czernin J, Sun K, Phelps ME, Schelbert HR. Effect of beta 1 adrenergic receptor blockade on myocardial blood flow and vasodilatory capacity. J Nucl Med 1997; 38: 442-6.

9. Bottcher M, Refsgaard J, Madsen MM, et al. Effect of antianginal medication on resting myocardial perfusion and pharmacologically induced hyperemia. J Nucl Cardiol 2003; 10: 345-52. 